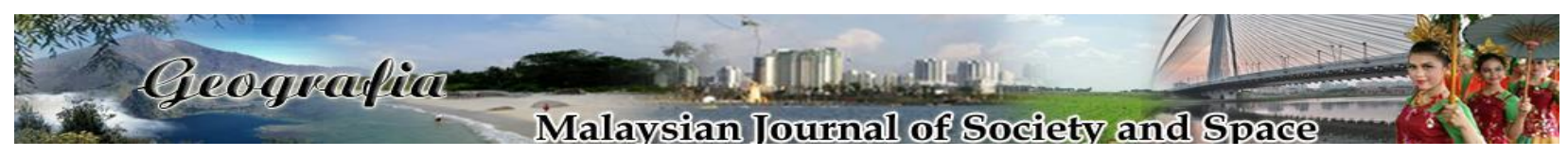

\title{
Gong dalam kehidupan golongan aristokrat Sebup, Kenyah di Sarawak
}

\author{
Nur Afifah Vanitha Abdullah \\ Pusat Kajian Bahasa, Kesusasteraan dan Kebudayaan Melayu, Fakulti Sains Sosial dan Kemanusiaan, \\ Universiti Kebangsaan Malaysia
}

Correspondence: Nur Afifah Vanitha Abdullah (email: nurafifah@ukm.edu.my)

Received: 02 March 2021; Accepted: 10 May 2021; Published: 29 May 2021

\begin{abstract}
Abstrak
Sebup adalah sebahagian suku kaum Kenyah di Sarawak. Masyarakat Sebup mendiami kawasan Long Loyang, di Miri. Masyarakat ini masih kuat mengamalkan beberapa budaya tradisi dan antaranya adalah berhubung dengan gong. Setiap keluarga aristokrat Sebup pasti memiliki sekurang-kurangnya sebuah gong dan lazimnya gong disimpan bersama bekalan beras di sebuah tempat khusus. Ruang penyimpanan khas bagi gong ini sudah cukup untuk menggambarkan kedudukan dan kepentingan gong dalam masyarakat Sebup. Peranan gong dalam konteks budaya Sebup melangkaui fungsi lazimnya sebagai sebuah alat muzik. Artikel ini bertujuan menerangkan fungsi gong dalam kitaran hidup golongan aristokrat Sebup. Untuk tujuan tersebut, sebuah kajian asas dirangka dengan reka bentuk kaedah kualitatif untuk memperoleh data. Memandangkan jurang ilmu yang agak ketara dalam subjek ini, maka temu bual dipilih sebagai kaedah utama bagi memperoleh data. Penyimpan adat masyarakat Sebup dan beberapa orang ahli masyarakat aristokrat yang berusia lebih 60 tahun ke atas dipilih sebagai informan. Dapatan kajian mendapati gong merupakan antara budaya bahan yang sangat penting dan berharga bagi golongan aristokrat Sebup. Gong adalah antara peralatan yang wajib ditampilkan dalam hampir kesemua upacara dalam kitaran hidup aristokrat Sebup. Gong wajib ditampilkan dan digunakan dalam upacara perkahwinan, pemberian status aristokrat dan kematian. Fungsi gong bagi golongan aristokrat masyarakat Sebup adalah sebagai komoditi, penunjuk kedudukan kewangan dan status sosial, manakala bunyinya adalah petanda situasi kecemasan bagi masyarakat Sebup.
\end{abstract}

Kata kunci: budaya material, gong, kajian etnik, Kenyah, Sarawak, Sebup

\section{Gong in the life of Sebup aristocrat in the Kenyah community of Sarawak}

\begin{abstract}
The Sebup community is a small part of the Kenyah ethnic in Sarawak and resides at Long Loyang, Miri. This community still practices its' traditional culture and among which is the gong. Every
\end{abstract}


Sebup aristocrat family will own at least one gong in their home and is kept in a special place with their rice reserves. The gong storage space indicates the status and importance of gong among the Sebup. In the cultural context of Sebup, it exceeds the typical function of a gong as a musical instrument. This article intends to explain the function of gong in the life cycle of a Sebup aristocrat. Thus, a fundamental research was planned with a qualitative research design to gather data. Interview was identified as the main research tool as there is a huge knowledge gap on this subject matter. The 'adat' authority and a few Sebup aristocrat members above 60 years of age were selected as informants to gather data. The findings of this research are that the gong is a very important and valuable material culture for the Sebup aristocrats. The gong is among the significant item in almost all rites in the life cycle of a Sebup aristocrat. The gong must be present and used during important ceremonies such as marriage, conferring of aristocrat status, and death. It serves as commodity, a financial and social status signifier, and its' sound indicates situation of emergency for the Sebup society.

Keywords: material culture, gong, ethnic studies, Kenyah, Sarawak, Sebup

\section{Pengenalan}

Etnik Sebup adalah sebahagian hampir empat puluh suku kaum yang tergolong dalam masyarakat Kenyah di Sarawak. Terdapat beberapa panggilan dengan ejaan berbeza bagi nama kaum ini antaranya adalah: Sebob, Sibub, Cebup, Sibop, Sibob dan Sebub. Penempatan asal etnik ini adalah di Batu Bora di Dataran Tinggi Usun Apau di Ulu Rejang (Francis, 2018; Micheal, 2018). Namun begitu masyarakat Sebup mula berhijrah dan menduduki kawasan-kawasan lain seperti Sungai Luar, Plieran dan Menawan apabila populasi mereka semakin meningkat di Dataran Tinggi Usun Apau. Salah satu kesan penghijrahan ini adalah kepada nama suku kaum Sebup itu sendiri. Ahli Sebup yang berpindah keluar dari tempat asal, kemudiannya mula meletakkan nama lokasi kediaman baharu kepada suku etnik mereka. Sehubungan itu, maka terdapat kaum Sebup misalnya Sebup Long Pekun, Sebup Long Menapa dan Sebup Long Temaja (Francis, 2018). Sejak awal 1800, masyarakat ini mula berpindah ke kawasan seperti Dapui, Paong dan Lobang di Ulu Tinjar (Micheal, 2021).

Masyarakat Sebup hidup dalam kelompok mereka sendiri. Lazimnya mereka akan hidup sebagai satu komuniti di satu lokasi dengan mendirikan rumah panjang. Struktur masyarakat ini adalah ringkas, iaitu terdapat golongan aristokrat (ketaw) atau kelas atasan dan ahli masyarakat kebanyakan (Micheal, 2021; Jerry, 2017). Mereka mempunyai Ketua yang terdiri daripada golongan aristokrat, yang juga merupakan pemegang adat. Ketua masyarakat ini bertanggungjawab dalam membuat keputusan dan bertindak sebagai tempat rujuk bagi sebarang masalah yang dihadapi oleh ahli masyarakatnya. Jawatan Ketua ini hanya dapat diwarisi oleh ahli keluarga aristokrat suku kaum ini. Namun begitu, jika keluarga aristokrat tiada waris maka Ketua akan dilantik daripada golongan masyarakat kebanyakan (panyen) di rumah panjang berkenaan (Micheal, 2018).

Gong adalah sebahagian daripada budaya bahan (material culture) dan harta pusaka keluarga yang penting bagi golongan aristokrat Sebup (Francis, 2018; Micheal, 2018). Gong ini diperbuat daripada tembaga dan terdiri daripada pelbagai saiz. Gong hanya dimiliki oleh golongan aristokrat masyarakat Sebup dan diperturunkan pemilikannya daripada satu generasi kepada generasi yang seterusnya. Setiap keluarga aristokrat Sebup pasti memiliki dan menyimpan 
sekurang-kurangnya sebuah gong. Rajah 1 berikut menunjukkan pelbagai saiz gong milik keluarga aristokrat Sabang Chapu, di Long Loyang.

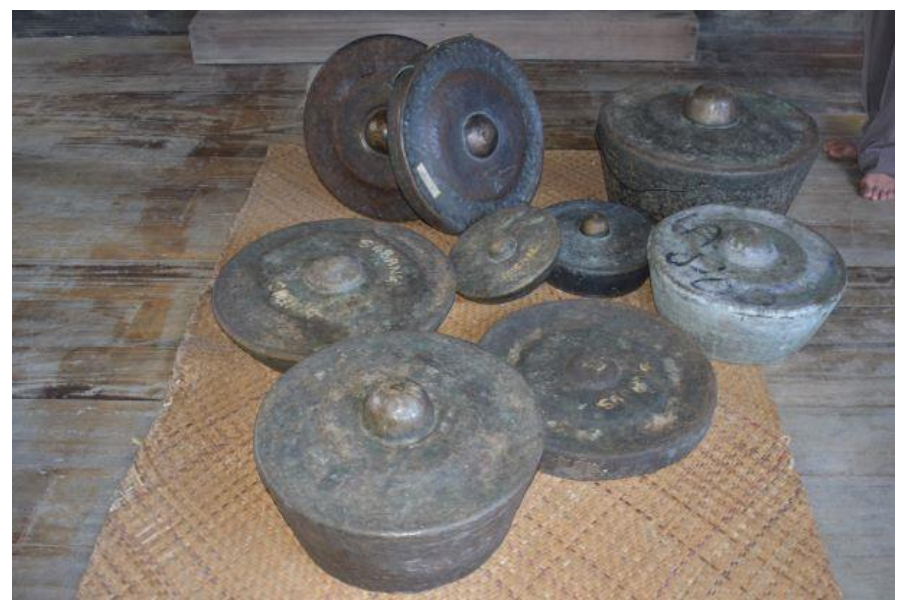

Sumber: Nur Afifah (2018)

Rajah 1. Gong milik keluarga Sabang Chepu.

Lazimnya dalam konteks kehidupan di rumah panjang masyarakat Sebup, gong disimpan bersama bekalan beras di dalam sebuah bangunan yang dikenali sebagai rumah padi (Francis, 2018). Bangunan khas ini terletak di halaman hadapan dan berdepan dengan anjung rumah panjang keluarga aristokrat Sebup. Rumah padi ini diperbuat daripada kayu, bersegi empat dan berbumbung, berkeluasan lebih kurang enam kaki kali empat kaki, serta berkedudukan tinggi lebih kurang enam kaki (Rujuk Rajah 2). Tangga mudah alih harus digunakan untuk memasuki ruang penyimpanan bekalan beras dan gong ini.

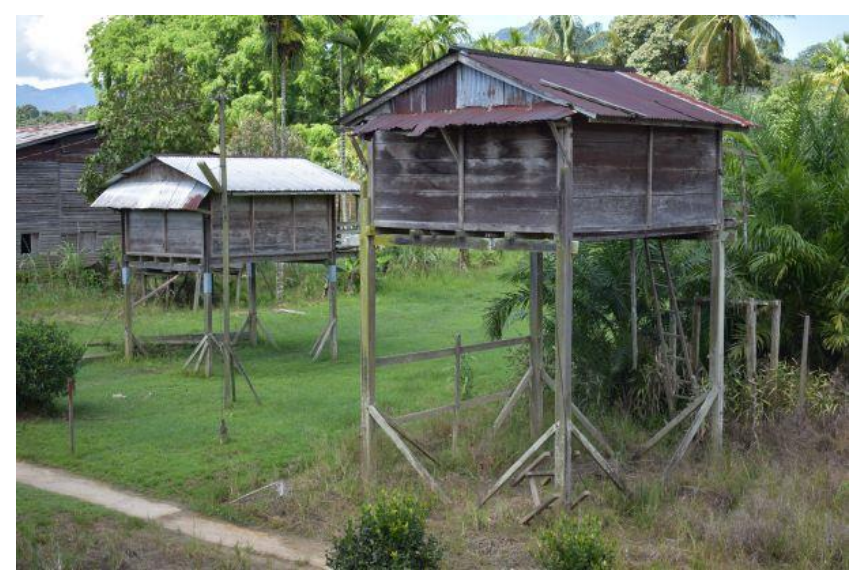

Sumber: Nur Afifah (2018)

Rajah 2. Rumah padi masyarakat Sebup.

Beras adalah suatu bahan yang sangat bernilai dan penting bagi masyarakat petani Sebup sehingga ke hari ini (Francis, 2018). Mengapakah gong yang lazimnya berfungsi sebagai alat muzik, bagi kebanyakan masyarakat umum diletakkan di sebuah tempat khusus bersama bekalan beras oleh masyarakat Sebup? Kewajipan memiliki gong oleh setiap keluarga aristokrat dan tempat 
penyimpanan gong ini menimbulkan persoalan, 'apakah fungsi gong dalam kehidupan masyarakat Sebup?' Sehubungan itu, artikel ini bertujuan menghuraikan fungsi gong dalam kehidupan aristokrat Sebup, di Long Loyang, Miri, Sarawak.

\section{Sorotan literatur}

Walaupun terdapat sejumlah kajian lepas tentang masyarakat Sarawak secara umum, namun penulisan tentang masyarakat Orang Ulu, khususnya masyarakat Sebup sangat terhad (Tan, 1997; Low, 2010; Suffian Mansor, 2016; Mohd Azlan Mis, 2012; Jeffrey, 2017; Suzanne anak Atar, Angelina Ansley \& Bilcher Bala, 2017; Junaidi Awang Besar, Novel Lyndon \& Mohd Azlan Abdullah, 2014; Salmah Omar, Philip Lepun \& Ribka Alan, 2016; Kwok, Chin Hoe \& Haris Abd. Wahab, 2013; A. Samad Kechot, Rahim Aman \& Shahidi A.H., 2017; Hong, 1978; Gregory Kiyai \& Noria Tugang, 2020; Fujica anak Anggo \& Louis Laja, 2018). Pendokumentasian tentang masyarakat Sebup sangat kurang sehingga hari ini. Sungguhpun begitu, terdapat korpus ilmu yang mengangkat masyarakat Kenyah-Kayan sebagai subjek kajian, yang meliputi aspek transformasi sosial, kraf tangan, perubahan sosiobudaya, dan seni 'tattoo'. Setakat ini, jurang ilmu masih ketara dalam pendokumentasian berkaitan peralatan gong dalam masyarakat ini.

Walaupun pendokumentasian tentang peralatan muzik masyarakat Kenyah-Kayan sangat terhad, namun terdapat satu penulisan artikel jurnal oleh A. Samad Kechot, Rahim Aman \& Shahidi A.H. (2017) yang membincangkan subjek persembahan gendang Melayu Sarawak, iaitu salah satu kaum dalam komposisi masyarakat Sarawak. Gendang Melayu Sarawak adalah satu ensembel seni persembahan tradisi dalam kalangan masyarakat Melayu Sarawak, yang merupakan instrumen penting dalam persembahan muzik ini. Gendang ini diperbuat daripada buluh dan kulit binatang. Kajian A. Samad Kechot, Rahim Aman \& Shahidi A.H. (2017) tertumpu di sekitar Kuching, Sarawak, yang membuat penelitian terhadap fungsi persembahan gendang Melayu Sarawak sebagai wadah kerjasama serta agen sosialisasi masyarakatnya semasa terlibat dengan penganjuran dan kegiatan kesenian tersebut. Artikel ini sebaliknya meneliti fungsi dan peranan gong dalam kalangan golongan aristokrat Sebup di kawasan Miri, Sarawak. Artikel oleh A. Samad Kechot dan artikel ini berbeza daripada segi subjek dan skop kajian. Namun begitu, kedua-dua artikel ini menyumbang kepada korpus ilmu budaya material secara umum, yang menyentuh tentang peralatan muzik secara khusus dalam kalangan masyarakat Sarawak.

\section{Metodologi}

Jurang ilmu yang agak ketara tentang masyarakat Sebup secara umum dan gong masyarakat ini secara khusus, adalah faktor utama kajian jenis fundamental atau asas dipilih untuk memperoleh data dan menjawab objektif kajian ini. Kaedah kualitatif dengan kajian lapangan dan temu bual dirangka sebagai reka bentuk kajian bagi memperoleh data daripada sumber primer. Rakaman audio visual dilakukan semasa temu bual. Rakaman audio visual temu bual ditranskripsikan dan kemudiannya dianalisis kandungannya bagi memperjelaskan secara terperinci fungsi gong dalam kalangan aristokrat Sebup, Long Loyang.

Kajian lapangan telah dilaksanakan di Long Loyang, Miri selama tiga hari, iaitu dari 2427 Julai 2018. Perjalanan ke Long Loyang memakan masa lebih kurang sembilan jam dengan menggunakan kenderaan pacuan empat roda dari lapangan terbang Miri. Keturunan aristokrat 
Sebup hanya terdapat di Long Loyang sahaja (Francis, 2018). Sementara itu masyarakat Sebup di lokasi lain pula hanya diketuai oleh keturunan orang kebanyakan. Terdapat dua buah keluarga Aristokrat di Long Loyang. Sebuah keluarga dikenali sebagai keturunan keluarga Sabang Chapu, manakala yang sebuah lagi dikenali sebagai keluarga Madang Balan (Micheal, 2018). Namun begitu, penulisan ini hanya memberi penumpuan terhadap keluarga aristokrat Sabang Chapu.

Sepanjang kajian lapangan, pengkaji telah menginap di rumah Ketua Penyimpan Adat masyarakat Sabang Chapu. Rumah ini lazimnya dijadikan rumah penginapan bagi mana-mana tetamu luar bagi komuniti ini. Kajian lapangan ini dilaksanakan agar penyelidik dapat memerhati dan memahami komuniti, dinamik sosial, adat, adab serta budaya material masyarakat ini secara langsung. Pengkaji juga telah merakam gambar-gambar pegun ketika melaksanakan kajian lapangan; antaranya rumah padi, gong, seni bina rumah panjang dan pakaian tradisi kaum Sebup, Long Loyang.

Data bagi menjawab persoalan kajian ini juga telah diperoleh melalui temu bual. Informan utama bagi temu bual adalah Ketua Penyimpan Adat kaum Sebup Long Loyang, Jeffery Sabang. Selain Ketua Penyimpan Adat, empat ahli masyarakat Sebup Long Loyang yang berusia lebih 60 tahun turut dipilih sebagai informan kajian. Empat informan ini terdiri daripada Micheal Sabang, aristokrat keturunan Sabang Chapu; Kapit Pur, isteri kepada Ketua Penyimpan Adat dan juga keturunan aristokrat etnik Kelabit. Kapit Pur telah melalui upacara menerima orang luar sebagai aristokrat Sebup setelah berkahwin dengan Francis Pingan Sabang. Seorang lagi informan kajian ini adalah Telun Liah Langet, seorang wanita keturunan aristokrat Sebup yang hilang status aristokratnya setelah berkahwin dengan suaminya yang bukan keturunan aristokrat. Ketua Penyimpan Adat dan juga Ketua Masyarakat Sebup, Francis Pingan Sabang, telah membantu untuk mengenal pasti informan kajian dalam kalangan ahli masyarakatnya bagi menepati kriteria informan kajian ini. Selain itu, Ketua Penyimpan Adat juga berperanan memanggil ahli komuniti Sebup yang terpilih untuk menyertai temu bual di rumah kediamannya. Kaedah pemilihan dan jemputan ini dilakukan kerana ahli komuniti Sebup sangat patuh dengan arahan Ketua mereka. Selain itu, Ketua juga sangat mengenali ahli komunitinya yang layak untuk ditemu bual. Kriteria calon informan adalah berusia lebih 60 tahun yang sihat tubuh badan, fikiran, pendengaran dan pertuturan agar data yang tepat, jelas dan sahih dapat diperoleh.

Pengkaji menggunakan bahasa Melayu untuk berkomunikasi dengan semua informan kajian. Khidmat juru bahasa Sebup turut digunakan sepanjang sesi temu bual bagi melancarkan proses komunikasi antara pengkaji dan informan. Isteri Penyimpan Adat, Kapit Pur telah bertindak sebagai penterjemah bahasa antara pengkaji dan informan dalam semua sesi temu bual bagi kajian ini. Kapit Pur, sangat fasih berbahasa Melayu dan bahasa Sebup.

\section{Dapatan kajian}

Artikel ini akan memperincikan fungsi gong dalam kitaran hidup ahli aristokrat Sebup, keturunan Sabang Chepu. Justeru, fungsi gong akan diperbincangkan dalam acara-acara penting dalam kehidupan ahli seperti perkahwinan dan kematian. Kegunaan gong sebagai komoditi untuk menebus maruah ahli keluarga aristokrat, dan peranannya dalam mengangkat kedudukan individu luar dalam masyarakat Orang Ulu turut dibincangkan. Sehubungan itu, perbincangan tentang fungsi gong dimulakan dengan acara perkahwinan, diikuti dengan kematian dan sebagai alat komunikasi serta simbol sosial bagi masyarakat Sebup. 


\section{Fungsi gong dalam perkahwinan}

Pemberian hadiah kepada pengantin wanita adalah salah satu amalan utama dalam acara perkahwinan masyarakat Sebup. Upacara perkahwinan dilaksanakan di rumah pihak pengantin wanita dan rombongan pengantin lelaki akan membawa hantaran semasa upacara ini. Dalam upacara perkahwinan golongan aristokrat, hadiah perkahwinan harus terdiri daripada lapan (8) jenis alat tembaga. Gong adalah hantaran wajib, paling penting dan utama dalam barisan hantaran. Selain gong, parang, saneng, gatong, tawak, selapak atau tepak sirih turut dijadikan hantaran oleh golongan aristokrat Sebup (Jerry; Kapit; Micheal 2018). Walaupun had Sarawak adalah lapan jenis peralatan tembaga, keluarga yang berkemampuan ekonomi akan menghadiahkan lebih daripada lapan jenis peralatan tembaga. Malah, saiz dan bilangan mana-mana hantaran tembaga ini juga amat Sarawak kedudukan ekonomi keluarga yang terlibat. Hantaran daripada pihak pengantin lelaki akan diletakkan di ruang rumah sebelum upacara perkahwinan dimulakan. Peragaan atau pameran ini bertindak sebagai pengumuman kepada para hadirin majlis tentang hadiah perkahwinan pihak pengantin lelaki kepada pengantin perempuan.

Dalam konteks hantaran atau hadiah perkahwinan ini, fungsi gong yang pertama sekali adalah sebagai alat indikator tentang kedudukan sosial sesebuah keluarga. Hanya golongan aristokrat sahaja yang dibenarkan menggunakan gong dan barang tembaga sebagai hantaran perkahwinan dalam masyarakat Sebup (Francis, 2018). Gong turut dijadikan kepala hantaran kerana gong hanya dimiliki oleh keluarga aristokrat. Hal ini berbeza dengan adat orang kebanyakan Sebup, kerana hantaran bagi golongan ini hanya kuali besi sahaja (Telun, 2018). Oleh yang demikian, pemberian gong sebagai hantaran secara tidak langsung menandakan bahawa keluarga yang terlibat dalam acara perkahwinan tersebut adalah golongan aristokrat.

Selain itu, hantaran gong dan tembaga ini turut menjadi indikator kepada kedudukan ekonomi keluarga pengantin. Jumlah bilangan setiap bahan hantaran dan saiz setiap satunya menjadi penanda aras kepada kedudukan kewangan keluarga pengantin lelaki. Perkara ini akan memberi gambaran latar belakang kedudukan ekonomi pengantin lelaki kepada keluarga pihak pengantin wanita yang menerimanya. Pada waktu yang sama, semua hadirin juga dapat menggarap status ekonomi pengantin lelaki tersebut. Secara tidak langsung hal ini akan memberi impak kepada kedudukan dan penerimaan pengantin lelaki dalam kelompok masyarakat keluarga baharunya itu.

Setelah mempamerkan hadiah perkahwinan, upacara perkahwinan akan diteruskan dengan pasangan pengantin duduk di atas gong duduk. Pasangan pengantin aristokrat Sebup wajib duduk sebelah-menyebelah atas gong duduk semasa upacara perkahwinan dilaksanakan. Pengantin lelaki akan duduk di sebelah kanan, manakala pengantin perempuan akan duduk di sebelah kiri gong. Saiz gong yang digunakan adalah sekitar 30 inci diameternya, dengan ketinggian sekitar 12 hingga 15 inci. Upacara ini akan dilaksanakan oleh seorang Ketua Upacara dalam kalangan masyarakat Sebup. Ketua Upacara ini lazimnya adalah Ketua Kampung ataupun ahli Jawatankuasa Kampung yang arif dengan adat perkahwinan masyarakat Sebup. Rajah 3 menunjukkan saiz gong yang dijadikan tempat duduk pengantin keluarga aristokrat Chepu. 




Sumber: Nur Afifah (2018)

Rajah 3. Gong duduk.

Protokol acara sebelum pasangan pengantin disahkan sebagai suami isteri adalah beberapa syarahan atau ucapan. Syarahan yang pertama adalah berhubung adat masyarakat Sebup. Adat ini akan diterangkan kepada pasangan pengantin dan khalayak yang hadir menyaksikan perkahwinan tersebut. Syarahan ini diikuti oleh nasihat hidup berkeluarga kepada pasangan pengantin oleh Ketua Upacara. Akhir sekali, ibu bapa kedua-dua pengantin akan menceritakan latar belakang anak masing-masing kepada khalayak. Hanya selepas selesai upacara ini, pasangan ini sah menjalani kehidupan suami isteri.

Keperluan pasangan pengantin Sebup duduk atas gong mempunyai fungsi dan makna tersendiri. Sepanjang hidup masyarakat aristokrat Sebup, hanya sewaktu perkahwinan sahaja gong dijadikan tempat duduk untuk pasangan pengantin. Hal ini disebabkan pasangan pengantin diraikan sebagai raja sehari semasa perkahwinan. Dalam konteks ini juga, pasangan pengantin dibenarkan duduk di atas gong, iaitu satu tingkat lebih tinggi daripada para tetamu yang duduk di atas lantai ketika upacara ini. Gong yang dijadikan tempat duduk pasangan pengantin adalah bahan budaya yang berharga dan penting bagi masyarakat ini. Ritual ini secara tidak langsung mengesahkan keturunan pasangan pengantin dan pada masa yang sama menunjukkan bahawa pasangan tersebut daripada keturunan baik serta berkedudukan tinggi dalam masyarakat itu.

Masyarakat aristokrat Sebup juga menerima menantu wanita dari luar keturunan aristokrat Sebup. Mereka mengamalkan perkahwinan antara ahli aristokrat Sebup dengan yang bukan aristokrat. Malah golongan aristokrat Sebup ini turut menerima ahli keluarga baharu daripada etnik lain. Namun begitu, dalam adat masyarakat Sebup terdapat satu ritual khusus yang harus dilalui oleh pengantin wanita bukan aristokrat. Ritual ini digelar 'metie'.

Ritual 'metie' harus dilalui oleh pengantin wanita luar 'ketaw' atau aristokrat apabila sampai buat kali pertama di rumah pengantin lelaki. Ritual ini dilaksanakan di anjung rumah keluarga lelaki 'ketaw'. Pengantin wanita luar tersebut harus mengangkat gong di khalayak ramai. Pada masa pengantin wanita mengangkat gong, Ketua Masyarakat akan mengumumkan bahawa pengantin tersebut telah menjadi sebahagian daripada ahli keluarga 'ketaw'. Hanya selepas ritual ini, maka pengantin wanita orang luar tersebut layak menerima segala hak dan penghormatan yang dikhaskan untuk golongan 'ketaw' dalam masyarakat Sebup (Kapit, 2018). Ritual ini sangat penting bagi masyarakat aristokrat Sebup. Hal ini demikian kerana, hanya pasangan yang melalui ritual ini sahaja yang layak melaksanakan perkahwinan melalui upacara duduk atas gong. Upacara 
penerimaan dan pengumuman sebagai ahli 'ketaw' juga penting, jika pasangan tersebut adalah pasangan yang akan mendiami serta mewarisi 'lamin biu', iaitu rumah pusaka. Kegagalan melalui upacara 'metie' semasa perkahwinan akan menyebabkan pasangan keturunan 'ketaw' dan warisnya kehilangan hak serta kedudukannya sebagai keturunan 'ketaw' dalam masyarakat Sebup buat selama-lamanya.

Ritual 'metie' ini bertindak sebagai pengumuman dan pengesahan status 'ketaw' seseorang individu. Gong dalam konteks ini adalah simbol bagi seorang bukan 'ketaw' diterima sebagai 'ketaw'. Upacara 'metie' ini tidak mungkin dapat dilalui tanpa gong kerana peralatan utama bagi pengesahan status 'ketaw' adalah gong. Dalam konteks upacara 'metie', kegagalan melaksanakannya akan mengakibatkan pasangan dan keturunan mereka tersingkir daripada golongan aristokrat Sebup.

\section{Fungsi gong dalam upacara memberi gelaran}

Terdapat satu lagi ritual dalam masyarakat keturunan 'ketaw' Sebup untuk memberi gelaran 'ketaw' kepada waris. Upacara ini dikenali sebagai 'Pucaw'. Ini adalah satu ritual yang melibatkan belanja yang agak lumayan. Sehubungan itu, lazimnya semua anak pasangan keturunan 'ketaw' akan dikumpulkan sekali gus untuk melaksanakan upacara memberi gelaran ini. Disebabkan hal ini, maka umur ahli keluarga 'ketaw' yang menjalani ritual 'pucaw' ini adalah daripada usia semuda bayi sehingga kepada remaja. Upacara ini diadakan dalam skala yang besar dan meriah berbanding kenduri perkahwinan masyarakat ini. Bilangan khinzir yang disembelih untuk acara ini adalah seekor untuk setiap seorang waris yang melalui ritual 'pucaw'. Selain khinzir, minuman wajib bagi upacara ini adalah jus halia yang dikenali sebagai 'remah'. Upacara 'pucaw' yang terbesar setakat ini dilaksanakan oleh Temenggong Uyong Lawai Jau, di Long San untuk cucunya sekitar tahun 1960-an. Jemputan bagi acara ini adalah dari semua masyarakat Kenyah di Baram pada ketika itu.

Dalam upacara 'pucaw', gong hanya dipamerkan sahaja. Kedudukan gong adalah di bahagian ruai rumah panjang. Bahagian rumah ini adalah yang paling di hadapan sekali di rumah panjang. Semua tetamu akan melalui bahagian ini sebelum masuk ke bahagian dalam rumah. Semua gong milik keluarga berkenaan akan dialas dengan kain songket dan dipamerkan di bahagian ini. Pameran gong sempena upacara 'pucaw' memiliki signifikan yang tersendiri. Peletakan gong di ruai rumah adalah adalah sebagai simbol dan bukti bahawa keluarga yang menganjurkan upacara tersebut adalah keturunan ketaw. Kehadiran gong dalam konteks ini adalah umpama tiket untuk tuan rumah bagi menganjurkan upacara tersebut. Hal ini juga bermakna bahawa upacara tersebut layak dilalui oleh waris keluarga yang menganjurkannya dan mereka layak diangkat sebagai keturunan 'ketaw' Sebup. Selain itu, ia juga adalah indikator kepada latar keturunan dan status ekonomi keluarga tersebut. Maksud di sebalik pameran tersebut adalah, jika mana-mana pihak berkeinginan atau berhajat menjadikan waris keluarga berkenaan sebagai menantu, tanda aras gong yang harus disediakan adalah seperti yang dipamerkan pada ruai rumah panjang tersebut.

\section{Gong dalam urusan menjaga maruah}

Dalam konteks isu sosial, gong turut digunakan untuk menyelesaikan masalah dalam kalangan masyarakat Sebup. Lelaki berketurunan 'ketaw' yang bersalah melakukan perbuatan zina akan dihukum dalam masyarakat ini. Sama ada lelaki berkenaan melakukan kesalahan tersebut dengan 
wanita bujang atau pun yang telah bersuami, dia harus tetap menerima hukuman. Lelaki yang didapati bersalah diwajibkan memberi peralatan gangsa yang dinamakan gatung atau canang kepada keluarga wanita berkenaan. Kedua-dua peralatan ini tergolong dalam keluarga gong. Tujuan pemberian tersebut adalah agar anak kandungan hasil perhubungan luar perkahwinan tersebut tidak ditimpa malapetaka. Malah, jika lelaki 'ketaw' tersebut telah berumah tangga, dia juga harus memberi gong kepada isterinya yang sah di khalayak umum. Perkara seperti ini akan diuruskan oleh Mahkamah Adat masyarakat Sebup. Sebaliknya, jika wanita 'ketaw' berzina dengan lelaki bukan 'ketaw', lelaki terbabit harus memberi sebuah gatung dan mengahwini wanita berkenaan.

Dalam konteks ini, masyarakat Sebup menjadikan gong sebagai alat penebus maruah. Maruah wanita Sebup, sama ada berketurunan 'ketaw' atau tidak, dapat ditebus oleh sebuah gong. Malah waris daripada perhubungan luar nikah tersebut juga terbela maruahnya dengan adat ini. Selain itu, kehadiran gong di sebuah keluarga yang bukan daripada keturunan 'ketaw' memberi indikasi bahawa dalam sejarah keluarga tersebut terdapat kes salah laku atau berzina dengan lelaki berketurunan 'ketaw'.

\section{Gong dalam upacara kematian}

Gong juga amat berperanan semasa proses upacara menguruskan jenazah dan berkabung bagi seorang ahli 'ketaw' Sebup. Paluan gong semasa upacara ini berbeza-beza tempo mengikut keperluan masa dan suasana dari waktu ahli 'ketaw' meninggal dunia sehingga tamat waktu berkabung. Sebaik sahaja terdapat kematian dalam kalangan ahli keluarga 'ketaw', maka gong akan dibunyikan di anjung tuan rumah si mati. Ini adalah paluan gong yang pertama. Paluan gong ini bertujuan memaklumkan kepada seluruh komuniti Sebup bahawa keluarga 'ketaw' berhadapan dengan kematian ahli keluarga. Ahli komuniti tidak dibenarkan menziarahi jenazah atau rumah keluarga 'ketaw' ketika ini. Mereka harus menunggu paluan gong kedua untuk menziarahi dan menyampaikan takziah kepada keluarga yang terbabit dalam kematian tersebut.

Paluan gong kedua hanya akan dibunyikan ketika jenazah dipindahkan dari dalam rumah ke anjung rumah keluarga 'ketaw'. Paluan ini pula bertujuan memanggil ahli komuniti Sebup yang mendiami kawasan persekitaran untuk menziarahi dan memberikan penghormatan terakhir kepada ahli 'ketaw' yang telah meninggal dunia. Selain dua paluan ini, gong turut dibunyikan dengan beberapa tempo berbeza lagi.

Lazimnya, masyarakat 'ketaw' Sebup hanya akan mengebumikan jenazah setelah semua kaum kerabat telah melaksanakan penghormatan terakhir. Hal ini akan memakan masa beberapa hari lamanya. Dalam proses menguruskan jenazah ini, terdapat satu lagi paluan gong yang menandakan terdapat tetamu jauh sedang menziarahi jenazah. Apabila ahli komuniti mendengar paluan tersebut, maka mereka harus beredar atau tidak menziarahi jenazah di rumah 'ketaw'. Hal ini bertujuan menghormati ruang dan masa keluarga 'ketaw' untuk bersendirian dengan tetamu jauh mereka. Selain itu, gong juga dipalu setiap hari selama lapan hari kematian di rumah 'ketaw'. Jumlah paluan gong akan mengikut bilangan hari berkabung bagi keluarga 'ketaw' yang kehilangan ahli keluarga mereka. Paluan gong bagi menandakan bilangan hari berkabung akan dilakukan pada waktu awal pagi, iaitu sekitar jam lapan.

Tujuan utama paluan gong semasa kematian seorang ahli keluarga 'ketaw' adalah sebagai alat komunikasi. Pada zaman sebelum kecanggihan alat komunikasi, gong digunakan sebagai isyarat untuk mengkhabarkan berita kematian dalam kalangan ahli keluarga 'ketaw'. Dalam ritual kematian, bilangan dan ritma paluan gong membawa makna berbeza kepada ahli masyarakat 
Sebup. Masyarakat Sebup sangat arif dan akur dengan bunyi paluan gong dalam konteks upacara kematian ahli keluarga Ketua mereka. Misalnya, paluan gong pertama yang 'monotone' dalam kiraan empat adalah tanda bahawa ahli keluarga 'ketaw' telah meninggal dunia. Oleh yang demikian, fungsi gong dalam proses menguruskan jenazah ahli keturunan 'ketaw' memiliki pelbagai indikasi, misalnya masa yang sesuai untuk menziarahi jenazah, masa untuk ahli keluarga tersebut harus bersendirian, dan kaedah menghitung bilangan hari berkabung bagi keluarga 'ketaw'.

\section{Fungsi lain gong dalam masyarakat Sebup}

\section{a. Semasa kecemasan}

Dalam masyarakat Sebup, gong juga akan dipalu secara berterusan dan nyaring dalam suasana genting atau malapetaka. Jika terdapat kebakaran atau banjir misalnya, gong akan dipalu agar semua ahli masyarakat bersiap sedia menghadapi situasi kecemasan tersebut. Dalam konteks ini, gong turut bertujuan sebagai alat komunikasi dalam masyarakat Sebup. Disebabkan fungsi bunyi paluan gong bertujuan untuk keadaan amat penting, maka ia disimpan di suatu tempat yang tinggi, iaitu di rumah padi. Kedudukan rumah padi di ruang halaman hadapan anjung rumah membolehkan ia dapat diperhati dan dipantau setiap waktu. Selain itu, kedudukan ruang menyimpan rumah padi yang sukar dicapai itu dapat membantu dan menjamin gong daripada dicapai atau diusik oleh kanak-kanak, mahupun individu tidak bertanggungjawab.

\section{b. Untuk mengangkat individu sebagai ketua}

Gong juga turut digunakan dalam upacara mengangkat seseorang sebagai ketua masyarakat Sebup. Namun begitu, upacara tersebut hanya boleh dilaksanakan jika individu tersebut juga daripada keturunan aristokrat. Misalnya Ketua Menteri Sarawak yang ke-enam, Datuk Patinggi Abang Haji Abdul Rahman Zohari bin Tun Abang Haji Openg telah diraikan dan diangkat sebagai Ketua oleh Persatuan Kebangsaan Orang Ulu Sarawak, pada bulan Disember 2017. Datuk Patinggi Abang Haji Abdul Rahman Zohari dijemput ke Miri untuk menjalani upacara ini, setelah beliau dilantik sebagai Ketua Menteri Sarawak pada 14 Januari 2017. Menurut Micheal Sabang (2018), yang juga merupakan salah seorang ahli jawatankuasa Persatuan Kebangsaan Orang Ulu Sarawak, Ketua Menteri Sarawak Keenam ini layak diraikan sebagai Ketua Masyarakat Sebup kerana beliau berketurunan 'Abang'. Justifikasi ini tepat kerana dalam stratifikasi sosial masyarakat Sarawak Sarawak, golongan masyarakat perabangan Sarawak Sarawak tergolong dalam ahli aristokrat.

Proses upacara mengangkat orang luar sebagai Ketua dilakukan dengan penuh istiadat. Lapan buah gong disusun lurus. Ketua orang luar ini harus berjalan atas susunan gong disaksikan semua Ketua kaum dan khalayak umum. Penyempurnaan ritual ini memadai untuk individu keturunan aristokrat luar diterima sebagai Ketua kaum Sebup. Dalam konteks Ketua Menteri Sarawak Keenam, beliau diangkat dan diraikan sebagai Ketua Masyarakat Sarawak, terutamanya Orang Ulu melalui upacara berjalan atas gong tersebut. Ia juga adalah simbol masyarakat tersebut dalam menyatakan sokongan padu dan penerimaan mereka terhadap Datuk Patinggi Abang Haji Abdul Rahman Zohari sebagai Ketua Menteri mereka. 


\section{Kesimpulan}

Gong mempunyai fungsi, makna dan nilai yang istimewa dalam budaya masyarakat Sebup. Walaupun gong lebih relevan dalam kehidupan golongan aristokrat Sebup, ia turut melibatkan ahli masyarakat Sebup dalam situasi kecemasan. Gong bukan sahaja memiliki nilai ekonomi, malah turut berfungsi sebagai simbol status sosial, penebus maruah dan alat komunikasi terutamanya ketika kecemasan dan malapetaka menimpa masyarakat Sebup. Oleh yang demikian, ternyata gong adalah sebahagian daripada budaya material masyarakat 'ketaw' Sebup yang penting dalam kitaran hidup mereka sejak perkahwinan sehinggalah ke upacara penyempurnaan jenazah ahli keluarga 'ketaw' Sebup.

\section{Penghargaan}

Artikel ini disempurnakan dengan Dana Penyelidikan Kerajaan Negeri Sarawak dan Dewan Bahasa dan Pustaka, Cawangan Negeri Sarawak yang bertajuk "Fungsi Gong dan Gendang Dalam Masyarakat Sarawak. SK-2018-007'.

\section{Rujukan}

A. Samad Kechot, Rahim Aman, \& Shahidi A.H. (2017). Komunikasi sosial dalam kalangan etnik Lembangan di Sadong: Gendang Melayu Sarawak. Jurnal Komunikasi: Malaysian Journal of Communication, 33(1), 158-172.

Astro Awani online. (14 Januari 2017). https://www.astroawani.com/foto-malaysia/abang-johariangkat-sumpah-ketua-menteri-sarawak-ke6-4187.

Francis Pingan Sabang. (2018). Kegunaan gong dalam masyarakat Sebup. Long Loyang, Sarawak. Temu bual, 21 Mac.

Fujica anak Anggo, \& Louis Laja. (2018). Traditional tattoo motifs as a symbol of social status of the women in Orang Ulu (Kayan-Kenyah) community in Sarawak. International Journal of Business and Management, 2(1), 7-11.

Gregory Kiyai, \& Noria Tugang. (2020). Artifak budaya masyarakat Iban: Warisan dan pusaka. Jurnal Kinabalu, 26(1), 59-71.

Hong, Evelyn. (1978). The process of sociocultural change in a Kenyah community. Akademika, 13, 31-44.

Jeffrey Ngau Lenjau. (2017). Transformasi sosial dalam etnik Kenyah Sang di Long San, Baram Sarawak. Journal of Borneo Kalimantan, 3(2), 62-72.

Junaidi Awang Besar, Novel Lyndon, \& Mohd Azlan Abdullah. (2014). Politik pilihan raya dan partisipasi politik Orang Ulu di Negeri Sarawak. Geografia-Malaysian Journal of Society and Space, 10(5), 135-147.

Kapit Pur. (2018). Adat perkahwinan masyarakat Ketaw Sebup. Long Loyang, Sarawak. Temu bual, 21 Mac.

Kwok, Chin Hoe, \& Haris Abd. Wahab. (2013). Sokongan politik dan penglibatan masyarakat dalam program pembasmian kemiskinan di Sarawak. Geografia-Malaysian Journal of Society and Space, 9(1), 89-97. 
Low Kok On. (2010). Lambang semangat juang dalam legenda Rentap dan sejarah penentangannya terhadap Raja Brooke di Sarawak. SARI-International Journal of the Malay World and Civilisation, 28(1), 151-175.

Micheal Sabang. (2018). Kegunaan gong dalam kalangan masyarakat Ketaw Sebup. Long Loyang, Sarawak. Temu bual, 21 Mac.

Micheal Sabang. (2021). Kegunaan gong dalam kalangan masyarakat Ketaw Sebup. Long Loyang, Sarawak. Temu bual, 8 Januari.

Mohd. Azlan Mis. (2012). Medium perantara pelbagai suku kaum di Sarawak: kajian lingua franca. GEMA Online Journal of Language Studies, 12(3) Special Section, 903-922.

Salmah Omar, Philip Lepun, \& Ribka Alan. (2016). Etnik dan pembentukan landskap budaya Malaysia: seni anyaman tikar Orang Ulu Sarawak. Geografia-Malaysian Journal of Society and Space, 12(10), 21-28.

Suffian Mansor. (2016). Pakatan politik berasaskan kaum: kerelevanan dan kelangsungan jawatan Timbalan Ketua Menteri Sarawak. JEBAT: Malaysian Journal of History, Politics and Strategic Studies, 43(2), 100-123.

Suzanne anak Atar, Angelina Ansley, \& Bilcher Bala. (2017). Fungsi dan cabaran Baruk sebagai warisan budaya Bidayuh. Jurnal Borneo Arkhailogia (Heritage, Archaelogy and History), 1(1), 113-141.

Tan Chee Beng. (1997). Indigenous people, the state and ethnogenesis: a study of the communal association of the "Dayak" in Sarawak Malaysia. Journal of Southeast Asian Studies, 28(2), 263-284.

Telun Liah Langet. (2018). Upacara-upacara penting dan adat istiadat dalam kalangan masyarakat Ketaw Sebup. Long Loyang, Sarawak. Temu bual, 20 Mac. 